\title{
CLINICAL FEATURES AND FACTORS AFFECTING THE SUCCESS OF RETINAL VASCULITIS THERAPY
}

\author{
Lia Meuthia Zaini ${ }^{1}$, Arief Sjamsulaksan Kartasasmita ${ }^{2}$ \\ ${ }^{1}$ Zainoel Abidin Hospital / Medicine Faculty Univ of Syiah Kuala, Banda Aceh \\ ${ }^{2}$ Cicendo Eye Hospital / Medicine Faculty Univ of Padjajaran, Bandung
}

\section{ABSTRACT}

Introduction: Retinal vasculitis is an inflammatory eye condition that threatens vision. Inflammation occurs in the branches of retinal arteries, cause by primary ocular diseases or associated with other diseases. This study aims to describe clinical features and factors affecting therapeutic success in 52 patients with retinal vasculitis.

Methods: This study was conducted using retrospective cohort in Retina Clinic of Cicendo Eye Hospital in vasculitis patients from January 1st- December 31st 2017. Data were collected retrospectively from the ophthalmic records of 52 patients (74 affected eyes). Descriptive analysis was performed on all data, chisquare and eksak fisher test were used to analyze risk factor and factors affecting the success of therapy.

Result: Out of 529 vasculitis and vitreous hemorrhage cases, retinal vasculitis was found in 52 patients (9.8\%). Mean age of retinal vasculitis patients were 42.3 years (range: $13-74$ years). 35 patients (62.3\%) were men and 22 patients (42.3\%) had bilateral retinal vasculitis. We also found $44,2 \%$ patients had a history of Toxoplasma infections, and $23.76 \%$ had a history of tuberculosis infections. At initial presentation, almost all patients (93.2\%) came with chief complaint of blurry vision, 42 patients (56.8\%) came with baseline visual acuity $\leq 20 / 200$. Vitreous hemorrhage was identified from retinal examination in 43 patients (58.1\%). Therapeutic success was found better in patients with underlying disease $(74,1 \%)$.

Conclusion: Most of the patients came with already bad condition. The main complaint was blurred vision $(<20 / 200)$ which may be related to vitreous hemorrhage. Most of the causes are tuberculosis and toxoplasmosis. Good management of course includes anti-inflammatory accompanied by therapy of the underlying disease. In this study, corticosteroid administration accompanied by antimicrobials (cotrimoxazole for toxoplasmosis and four drug regimens (RHZE) for ocular tuberculosis) seems to have a good respond to retinal vasculitis associated with toxoplasmosis and tuberculosis

Keywords: retinal vasculitis, vitreous hemorrhage, vitreous opacity

Cite This Article: ZAINI, Lia Meuthia. Clinical Features and Factors Affecting the Success of Retinal Vasculitis Therapy in Cicendo Eye Hospital, Bandung. Januari-December 2017. International Journal of Retina, [S.I.], v. 3, n. 2, sep. 2020. ISSN 2614-8536.

Available at: https://www.ijretina.com/index.php/ijretina/article/view/118

\section{INTRODUCTION}

*Correspondence to: Lia Meuthia Zaini, Department of Ophthalmology, Zainoel Abidin Hospital/ Medicine Faculty, Univ of Syiah Kuala

lia_mzaini@unsyiah.ac.id
Retinal vasculitis is a group of diseases vessels, including perivascular sheathing, characterized by inflammation of the retinal vascular leakage, and occlusion. ${ }^{2}$ arteries. ${ }^{1}$ Based on the consensus of the Incidence of retinal vasculitis is 1-2 per Standardization of Uveitis Nomenclature $10.000 .{ }^{3}$ In a study conducted in North Working Group in November 2004, retinal America, retinal vasculitis was found in $15 \%$ of vasculitis is a term used to describe uveitis patients, of which $17 \%$ of the cases were inflammation and changes in retinal blood isolated retinal vasculitis. ${ }^{4}$ 
Another study conducted by Sarief $L$, et al found that retinal vasculitis was found in $6-15 \%$ of uveitis patients. ${ }^{5}$

The findings seen on funduscopic examination are usually from venous sheathing to vascular damage that affects the permeability of blood vessel walls. This results in leakage of blood into the retinal extracellular space and cystoid macular edema. Non-perfused area of the retina can cause permanent visual loss, especially when ischemia occurs in the macula. In addition, neovascularization can cause recurrent vitreous hemorrhage and ultimately results in retinal detachment, rubeosis iridis, and neovaskular glaucoma, which can cause vision loss. ${ }^{5}$

The prognosis of patients with retinal vasculitis varies greatly, and is determined by the underlying disease, degree of inflammation, and location of the affected retinal blood vessels. ${ }^{1}$ Complication that can occur in patients with retinal vasculitis are quite severe. Ischemic retinal vasculitis has a very poor visual outcome compared to retinal vasculitis that is not accompanied by ischemic condition. Other events that can worsen the disease are retinal detachment, macular edema, vascular occlusion, neovascularization, and the formation of epiretinal membrane that greatly affect vision. ${ }^{1}$ One thing to note in retinal vasculitis is the heterogeneity of this disease. The cause is numerous and patient's characteristics also vary. ${ }^{2}$ The limitation of supporting examinations experience in most hospitals in Indonesia is the reason for the need to find this characteristic of disease. Therefore, this study was conducted to determine the clinical characteristic of retinal vasculitis patients at the national eye referral center, and assess the factors that influence the success of therapy.

\section{METHOD}

This study was a retrospective cohort study of retinal vasculitis patients who came to the retinal clinic at Cicendo Eye Hospital, Bandung from 1 January to 31 December, 2017. Diagnosis of retinal vasculitis was made by retinal doctors who served in retinal clinic when patients came for treatment.

\section{Data collection}

Data collection was performed by evaluating the medical record. Medical record data was collected by Hospital Information and Technology (IT) personnel by tracking patients who seek treatment throughout 2017 with the ICD 10 for retinal vasculitis (H.35.06), vitreous hemorrhage (H.43.1), and other vitreous opacities (H.43.39).
Data was provided to two hospital medical record officers to collect medical records. Through the collected medical records, patient's data such as personal data, diagnosis, treatment, visual acuity during the first visit, 1 month after treatment, and 3 months after treatment are recorded. Positive laboratory results were also taken.

All figures, tables, or informative illustrations are prepared as image file.

\section{Data management and statistical analysis}

All medical records that meet the ICD 10 code above are collected and recorded. Medical records with a diagnosis of retinal vasculitis will be analyzed directly, while cases with a diagnosis of vitreous hemorrhage or vitreous opacification, we first determined its etiology. Only medical records with cases of retinal vasculitis were further analyzed. Demographic and clinical characteristics data in the medical records are recorded. To find out whether age and sex are risk factors or not, a chi-square analysis was performed. Data on all vasculitis patients ( 52 patients), compared with 52 other patients such as non-vasculitis vitreous hemorrhage. Sampling of non-vasculitis patients was taken randomly. Then an assessment of the factors affecting the success of therapy is carried out. The factors assessed are the presence or absence of underlying diseases, initial visual acuity, and type of therapy.

Therapy is considered good/successful if there were reduction or loss of vitreous opacification, reduction or loss of infiltrates, and / or increases vision. Therapy is considered not good or fails if vitreous opacification increases, exudate or infiltrates increase, regressions occur such as exudative retinal detachment, or traction retinal detachment. Systemic disease and underlying disease were seen from the diagnosis of other doctors (internist) who are consulted by retinal specialist at the retinal clinic. Assessment of factors affecting the success of therapy was only done in patients who returned for control at month 1 and / or month 3. Whereas patients who only came once were not include in the analysis. The Chi Square and Fisher Exact statistical tests were performed to assess the relationship.

\section{RESULTS}

Total medical records found by hospital medical records staff using the specified ICD 10 code are 853 medical records. However, 324 of them had to be excluded because they were not cases of vasculitis or vitreous opacities. Of the 529 medical records obtained, 52 cases of vasculitis $(9,8 \%)$ were found, and it was the second most common disease after diabetic retinopathy 
(300 cases). Other cases found were vitreous hemorrhage caused by age related macular degenerations (37 cases), retinal vein occlusions (34 cases), trauma (20 cases), posterior vitreous detachment (19 cases), retinal detachment (17 cases), and polypoidal choroidal vasculopathy (1 cases). There were also 49 cases of unknown vitreous bleeding.

The demographic characteristics of the patients such as age, sex, bilaterality, and history of systemic disease shown in table 1. In follow up period shown that 10 peoples did not come for control in the first and /or third moths, which might be due to an improve eye condition, or because they wanted control to another hospital. This caused that the ten patients could not be analyzed to determine the success factors of management.

Table 1. Demographic characteristics

\begin{tabular}{|c|c|c|c|}
\hline No & Characteristics & $\begin{array}{c}\text { Amount } \\
(n=52)\end{array}$ & Percentage \\
\hline \multirow[t]{4}{*}{1} & Age & & \\
\hline & Mean \pm SD & $42.3 \pm 14.6$ & \\
\hline & Median & 42 & \\
\hline & Range & $13-74$ & \\
\hline \multirow[t]{3}{*}{2} & Sex & & \\
\hline & Male & 35 & 67.3 \\
\hline & Female & 17 & 32.7 \\
\hline \multirow[t]{9}{*}{3} & $\begin{array}{l}\text { History of systemic } \\
\text { diseases and possible } \\
\text { related diseases }\end{array}$ & & \\
\hline & Tuberculosis & 12 & 23.0 \\
\hline & Diabetes Mellitus & 2 & 3.8 \\
\hline & Hypertension & 13 & 25.0 \\
\hline & Autoimmune disease & 2 & 3.8 \\
\hline & Toxoplasmosis & 23 & 44.2 \\
\hline & Cytomegalovirus & 19 & 36.5 \\
\hline & Rubela & 21 & 40.4 \\
\hline & Herpes Symplex Type 1 & 30 & 57.7 \\
\hline \multirow[t]{3}{*}{4} & Bilaterality & & \\
\hline & Bilateral & 22 & 42.3 \\
\hline & Unilateral & 30 & 57.7 \\
\hline \multirow[t]{4}{*}{5} & Follow up period & & \\
\hline & No follow up & 10 & 19.23 \\
\hline & 1 month & 11 & 21.53 \\
\hline & $\geq 3$ months & 31 & 59.61 \\
\hline
\end{tabular}

The clinical characteristics of vasculitis patients shown in table 2. Data were taken at the time the patient first came to the hospital. Data presentation is based on complaints and symptoms felt in each eye. Of all the analyzed medical records, there were 22 patients affected by vasculitis in both eyes, so there were total of 74 eyes analyzed. Each patient can have one or more symptoms at a time.

Risk factor analysis is shown in table 3. Age and sex appear to have a significant relationship with the incidence of retinal vasculitis. Age 30-39 years has the greatest risk for vasculitis, which is 9.21 times compared with age $\geq 50$ years; men have a risk of vasculitis 3.04 times greater than women.

Table 4 shows the factors affecting the success of vasculitis therapy. In this table, assessments are also carried out in each eye. A total of 74 eyes will be analyzed. As mention before, because there were 10 peoples (17 eyes) that did not come for control in the first and third months, so these 17 eyes had to be excluded. Therefore, there were 57 eyes analyzed to assess the success of therapy. For the type of therapy given, we classify it as a drug, surgery, corticosteroid, and also a combination of these therapies. Drugs are therapies administered to manage the underlying disease, while surgery is pars plana vitrectomy performed because of severe vitreous opacity or hemorrhage.

\section{Table 2. Clinical characteristics}

\begin{tabular}{llcc}
\hline No & Characteristics & $\begin{array}{c}\text { Amount } \\
\text { (n=74 } \\
\text { eyes) }\end{array}$ & Percentage \\
\hline $1 \quad$ UCVA & & \\
& $\geq 20 / 50$ & 18 & 24.3 \\
& $20 / 50-20 / 160$ & 14 & 18.9 \\
& $\leq 20 / 200$ & 42 & 56.8 \\
\hline 2 Symptoms & & \\
& Blurred & 69 & 93.2 \\
& Floaters & 29 & 39.2 \\
& Photopsia & 18 & 24.3 \\
Pain & 7 & 9.5 \\
& Visual field defect & 6 & 8.1 \\
Headache & 2 & 2.7 \\
Eyelid edema & 2 & 2.7 \\
Redness & 2 & 2.7 \\
Halos around light & 1 & 1.4 \\
Dazzled & 1 & 1.4 \\
No symptoms & 4 & 5.4 \\
\hline
\end{tabular}


3 Fundus

Vitreous hemorrhage $\quad 43 \quad 58.1$

Vitreous fibrosis $\quad 25 \quad 33.8$

Exudate $\quad 30 \quad 40.5$

$\begin{array}{lll}\text { Sheathing } & 39 & 52.7\end{array}$

Ghost vessels $\quad 16 \quad 21.6$

$\begin{array}{lll}\text { Pre-retinal hemorrhage } & 7 & 9.5\end{array}$

$\begin{array}{lll}\text { Vitreous cells } & 7 & 9.5\end{array}$

Retinal hemorrhage $\quad 3 \quad 4.1$

$\begin{array}{lll}\text { Sclerotic vessel } & 2 & 2.7\end{array}$

Exudative RD 2.7

Scar 2.7

$\begin{array}{lll}\text { Fibrovascular membrane } & 2 & 2.7\end{array}$

Retinal Ischemia $\quad 1 \quad 1.4$

Shunt vessel $\quad 1 \quad 1.4$

$\begin{array}{lll}\text { Tortuous vessel } & 1 & 1.4\end{array}$

\section{$4 \quad$ Anterior Segment}

$\begin{array}{lll}\text { Cataract } & 17 & 23.0\end{array}$

Keratic precipitate $\quad 9 \quad 12.2$

Ciliary injection $\quad 4 \quad 5.4$

Cells/flare $\quad 3 \quad 4.1$

Synechiae $\quad 1 \quad 1.4$

$\begin{array}{lll}\text { Pseudophakic } & 1 & 1.4\end{array}$

$\begin{array}{lll}\text { No abnormalities } & 39 & 52.7\end{array}$

In table 4 it appears that factor affecting the success of therapy is the presence of underlying disease. Patients who had underlying disease were more successful in the treatment than those without underlying disease (74.1\% vs $46.7 \%)$ and this difference was statistically significant $(p<0.05)$. Details of the underlying disease and treatment provided can be seen in table 5 . Out of a total of 57 eyes, only 27 eyes found with underlying disease. Those diseases were Toxoplasmosis, Tuberculosis, and Cytomegalovirus.

Table 3. Risk factor

\begin{tabular}{clcccc}
\hline \multirow{2}{*}{ No } & Risk factor & \multicolumn{2}{c}{ Retinal vasculitis } & P Value & OR (95\% Cl) \\
\cline { 2 - 3 } & & Yes $(\mathbf{n}=\mathbf{5 2})$ & No $(\mathbf{n}=\mathbf{5 2})$ & & \\
\hline 1 & Age & 10 & 5 & 0.002 & $4.25(1.25-14.5)$ \\
& $<30$ years & 13 & 3 & $9.21(2.30-36.93)$ \\
& $30-39$ years & 13 & 10 & $2.76(1.00-7.63)$ \\
& $40-49$ years & 16 & 34 & 1.0 \\
& $\geq 50$ years & $42.3 \pm 14.6$ & $50.4 \pm 12.5$ & & \\
& Mean \pm SD & 42 & 52 & & $3.04(1.27-7.36)$ \\
\hline
\end{tabular}

Note: $\left.{ }^{*}\right)$ Based on the chi-square test; OR $(95 \% \mathrm{Cl})=$ Odds ratio and Confidence Interval $95 \%$

Table 4. Factor affecting the success of therapy

\begin{tabular}{|c|c|c|c|c|c|}
\hline \multirow[t]{2}{*}{ No } & \multirow{2}{*}{$\begin{array}{l}\text { Factor } \\
\text { affecting } \\
\text { therapy }\end{array}$} & \multirow[t]{2}{*}{ Details } & \multicolumn{2}{|c|}{ Therapeutic results } & \multirow[t]{2}{*}{ P Value } \\
\hline & & & Improve & $\begin{array}{c}\text { No improvement/ } \\
\text { Worse }\end{array}$ & \\
\hline \multirow[t]{2}{*}{1} & Underlying & Yes & $20(74.1 \%)$ & $7(25.9 \%)$ & 0.037 \\
\hline & diseases & No & $14(46.7 \%)$ & $16(53.3 \%)$ & \\
\hline \multirow[t]{2}{*}{2} & Initial visual & $<20 / 200$ & $13(54.2 \%)$ & $11(45.8 \%)$ & 0.472 \\
\hline & acuity & $\geq 20 / 200$ & $21(63.6 \%)$ & $12(36.4 \%)$ & \\
\hline \multirow[t]{5}{*}{3} & Therapy & Drugs & $1(50.0 \%)$ & $1(50.0 \%)$ & 0.137 \\
\hline & & Drugs + Steroid & $22(55.0 \%)$ & $18(45.0 \%)$ & \\
\hline & & Drugs + Steroid + Surgery & $8(88.9 \%)$ & $1(11.1 \%)$ & \\
\hline & & Surgery & $2(100 \%)$ & $0(0.0 \%)$ & \\
\hline & & Observation & $1(25.0 \%)$ & $3(75.0 \%)$ & \\
\hline
\end{tabular}

Note: ${ }^{*}$ ) Based on the Chi-Square test except for the Therapy using Fisher Exact test 
Table 5. Underlying Disease and its management

\begin{tabular}{|c|c|c|c|c|c|}
\hline No & $\begin{array}{l}\text { Underlying } \\
\text { disease }\end{array}$ & Therapy & Dose & Route & Total \\
\hline \multirow[t]{2}{*}{1} & Toxoplasmosis & Cotrimoxazole & $2 \times 960 \mathrm{mg}$ & Oral & 12 \\
\hline & & Methylprednisolone & $1 \mathrm{mg} / \mathrm{BW}$ & Oral & \\
\hline \multirow[t]{3}{*}{3} & Toxoplasmosis & Cotrimoxazole & $2 \times 960 \mathrm{mg}$ & Oral & 2 \\
\hline & & Methylprednisolone & $1 \mathrm{mg} / \mathrm{BW}$ & Oral & \\
\hline & & Surgery & - & Parsplana Vitrectomy & \\
\hline \multirow[t]{3}{*}{4} & Tuberculosis & Methylprednisolone & $1 \mathrm{mg} / \mathrm{BW}$ & Oral & 2 \\
\hline & & Surgery & - & Parsplana Vitrectomy & \\
\hline & & TB drugs* & & & \\
\hline \multirow[t]{2}{*}{5} & Tuberculosis & Methylprednisolone & $1 \mathrm{mg} / \mathrm{BW}$ & Oral & 8 \\
\hline & & TB drugs* & & Oral & \\
\hline \multirow[t]{2}{*}{6} & Cytomegalovirus & $\begin{array}{l}\text { Ganciclovir } \\
\text { ARV** }\end{array}$ & $2 \mathrm{mg}$ & Intravitreal & 3 \\
\hline & Total & & & & 27 \\
\hline
\end{tabular}

\section{DISCUSSION}

From all the medical records traced, we found that the most frequent cause of vitreous bleeding was diabetic retinopathy. Retinal vasculitis was the second most with a prevalence of $9.8 \%$. Chi-square test found that the age of 30-39 years statistically proven to have the greatest risk of suffering from retinal vasculitis, and men had the possibility of suffering from vasculitis 3.04 greater that women. Previous studies of the causes of vitreous hemorrhage and the age range of vasculitis sufferers mostly have the similar results with this study. 1,6-8 Research explaining that there is no significant difference between sexes, one of which is a study conducted by Shulman et al, in Israel that did not find any gender predisposition in patients with noninfectious retinal vasculitis. ${ }^{9}$

A Characteristics of retinal vasculitis is that the diagnosis made clinically based on funduscopic examination and from supporting investigation such as fluorescence angiography. Biopsy examination for histological confirmation is not carried out because of the risk. This is what distinguishes retinal vasculitis from systemic vasculitis., ${ }^{4,10}$ Fluorescence angiography is a very important examination in this case. This procedure is actually quite safe in healthy people, but with a history of any systemic disease. ${ }^{11}$ This examination is currently not possible at our hospital, and almost all hospital in Indonesia. Therefore, it is unfortunate that we could not get the results of fluorescein angiography. So, in this study we can only got clinical findings on the retina by ophthalmoscopy examination. Ischemic area which is one of the most important factors in the management of retinal vasculitis could not be evaluated. It is surprising that out of a total of 74 eyes evaluated, 68 of them came with vitreous opacity. Forty-eight of them came with initial visual acuity less then 20/200. This means that most patients came for treatment after severe eye complications.

Another thing about retinal vasculitis is their relationship with infection. Systemic vasculitis is rarely caused by an infection process, whereas retinal vasculitis is often associated with the infection (Tuberculosis, TORCH, Syphilis and other viral infection). Other diseases that can be associated with retinal vasculitis are Bechet's, Sarcoidosis, Multiple Sclerosis, Collagen-vascular disease, Sympathetic Ophthalmia, and others. ${ }^{2,5,12,13}$ Retinal vasculitis can also be a part of posterior uveitis, where this disease is found in $6-15 \%$ of patients with posterior uveitis. Our study found that the history of TORCH infection was the most frequent systemic disease compare to other diseases. If we look at the number of cases, our finding was somewhat different from vasculitis or uveitis cases in other developing countries, where tuberculosis is the most common cause. ${ }^{14,15} \mathrm{We}$ didn't carry out further statistical analysis for this finding. Limited laboratory facilities and public financial problems have caused a number of cases not to undergo a complete laboratory examination, 
so we only carried out examinations that are considered the most important. The initial visual acuity, signs, and symptoms experience by most patients were in line with other theory and study that has been done before. ${ }^{2,15-17}$ Management of retinal vasculitis depends on the underlying disease. Non-infectious retinal vasculitis is treated with corticosteroids and / or immunosuppressive agents, whereas infectious retinal vasculitis is given antimicrobials. ${ }^{1}$ However, the success of therapy is determined by many factors. In this study, we analyzed the factor affecting the success of therapy. It was found that patients with systemic disease had better therapeutic success compared to those who did not have any systemic disease. This finding was statistically significant, perhaps because the cause of the disease has been detected, so treatment for the underlying disease can also be done. While patients who did not have an underlying disease may be because they did not have it or it was not detected. So, procedure for the underlying disease could not be performed. Other indicators such as initial visual acuity and type of treatment did not affect the success of therapy. This study confirms previous studies by Jennifer $\mathrm{H}$. Ku et al, who found that patients with systemic infections and poor initial vision had better visual outcome. ${ }^{2}$

This study has several limitations such as a retrospective design, so some of the required data was not stated in incomplete medical records. The evaluation period was quite short causing a limited number of subjects. A very important angiographic examination could not be performed, making it difficult to evaluate the ischemic area. Fundus description can only be seen from sketch drawings, there were no picture of fundus photograph. The limited laboratory facilities that occur in almost all hospitals in Indonesia caused many underlying diseases could not be evaluated.

\section{CONCLUSION}

Retinal vasculitis is a quite common disease found in retinal clinics. Although mostly idiopathic, associations with systemic conditions are also frequently reported. Financial problem and limitations of diagnostic facilities (mainly laboratories) occur in almost all hospital in Indonesia. So, the ophthalmologist must be able to choose examinations that are really needed to confirm the diagnosis and treatment. This study and several studies of retinal vasculitis in developing countries conclude that the tuberculosis, TORCH, and autoimmune test are important examination in the management of retinal vasculitis. The presence of the underlying diseases is one of the success factors, this is probably because the therapy is not only steroids, but also drugs that were directly targeted to the underlying disease, such as addition of cotrimoxazole for toxoplasmosis or Tuberculosis drugs for vasculitis in ocular tuberculosis.

\section{REFERENCES}

1. Mir TA, Reddy AK, Burkholder BM, Walsh J, Shifera AS, Khan IR, et al. Clinical Feautures and Incidence Rates of Ocular Complications in Patients With Retinal Vasculitis. Am J Ophthalmol. 2017;179:171-8

2. $\mathrm{Ku} \mathrm{JH}$, Ali A, Suhler EB, Choi D, Rosenbaum JT. Characteristics and visual outcome of patients with retinal vasculitis. Arch Ophthalmol. 2012;Vol.130(10) 1261-64

3. Hughes EH, Dick AD. The pathology and pathogenesis of retinal vasculitis. Neuropath appl neuro. 2003; 114(5):593-599

4. Pelegrín L, Hernández-Rodríguez J, Espinosa G, Llorenç V, Sainz-de-la-Maza M, Fontenla JR, et al. Characterization of isolated retinal vasculitis. Analysis of a cohort from a single center and literature review.

5. Sharief L, Lightman SUE, Blum-hareuveni T, Bar A, Tomkins-netzer O. Clinical Outcome of Retinal Vasculitis and Predictors for Prognosis of Ischemic Retinal Vasculitis. Am J Ophthalmol 2017;177:206-12.

6. Rishi P, Rishi E, Gupta A, Swaminathan M, Chhablani J. Vitreous Hemorrhage in Children and Adolescents in India. J AAPOS. 2013; Vol.17(1)64-9

7. Sudhalkar A, Chhablani J, Rani PK, Jalali S, Balakrishnan $D$, Tyagi M. Bilateral vitreous hemorrhage in children: Clinical features and outcomes. J Ophthalmic Vis Res. 2015;Vol.10(2)139-43.

8. Agrawal R, Gonzalez-lopez JJ, Cardoso J, Gupta B. Peripheral Retinal Vasculitis. Retina. 2017;37:112-7.

9. Shulman S, Kramer M, Schaap-fogler M, Habot-wilner Z. Characteristics and Long-Term Outcome of Patients with Noninfectious Retinal Vasculitis. Retina 2015; 35 2633-40.

10. Mesquida $M$, Llorens $V$, Adán A. New imaging techniques in retinal vasculitis. Med Clin (Barc) 2017;149(6)261-6.

11. Yang Yi, Mai J, Wang J. Risk factors for adverse reactions of fundus fluorescein angiography. Eye Sci. 2016;Vol.31(2)86-91.

12. Rosenbaum JT, Ku J, Ali A, Choi D, Suhler EB. Patients with Retinal Vasculitis Rarely Suffer from Systemic Vasculitis. Semin Arthritis Rheum. 2012; Vol.41(6) 85965.

13. Do BK, Giovinazzo J. Retinal Vasculitis. Adv Ophthalmol Optom. 2016; Vol.1(1) 69-84.

14. Apinyawasisuk $S$, Rothova A, Kunavisarut $P$, Pathanapitoon K. Clinical Features and Etiology of Retinal Vasculitis in Northern Thailand. Indian $J$ 
Ophthalmol. 2013;(Dec)739-42

15. Walton RC, Ashmore ED. Retinal vasculitis. Curr Opin Ophthalmol 2003;14: 413-9.

16. Milston R, Madigan MC, Sebag J. Vitreous floaters: Etiology, diagnostics, and management. Surv Ophthalmol 2016;Vol.61(2)211-27.

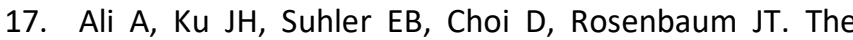
course of retinal vasculitis. Br J Ophthalmol. 2014; 98: 785-9.

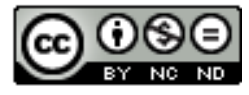

This work licensed under Creative Commons Attribution 